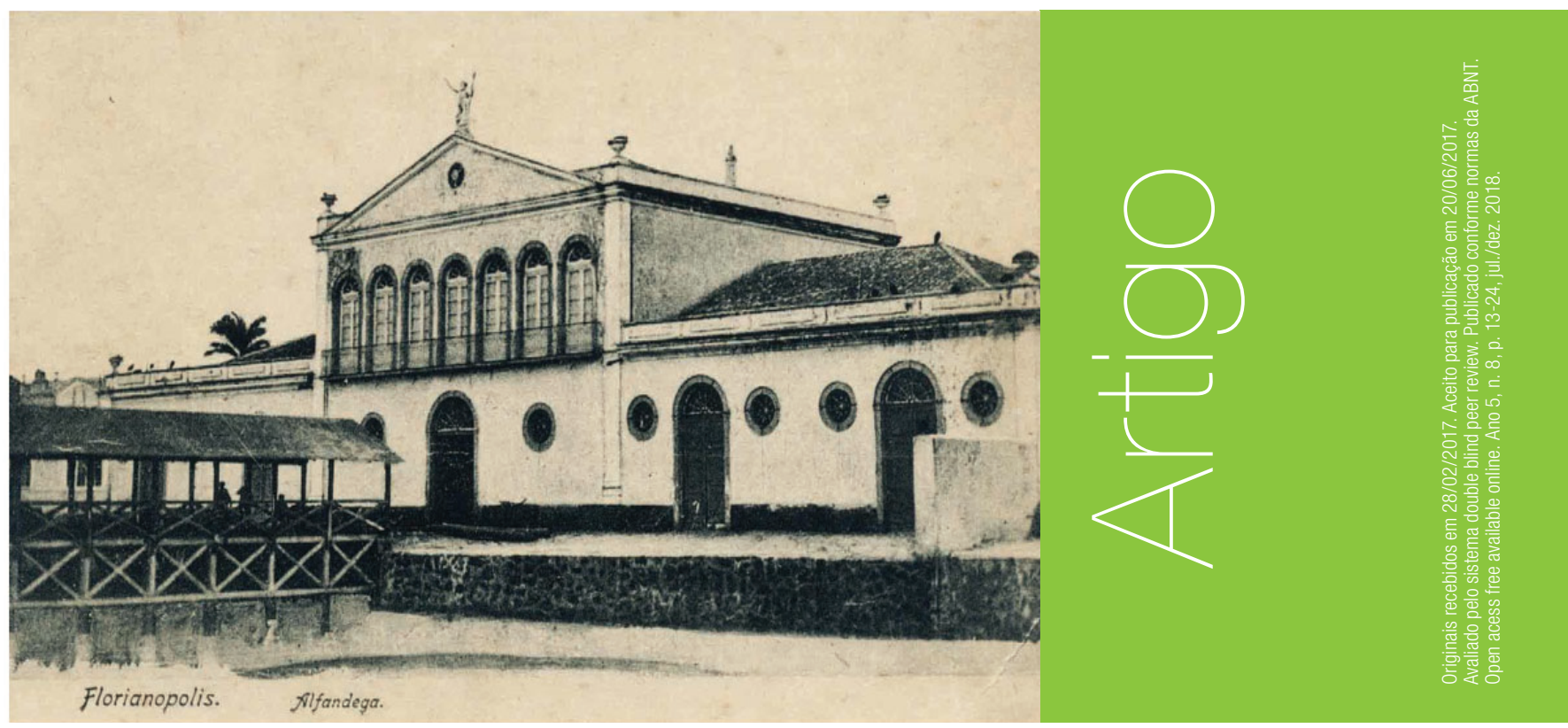

\title{
Caminhando pelas ruas de Desterro - Santa Catarina - Brasil $^{1}$
}

\author{
Maria Helena Alemany Soares² - maria.helena@ifsc.edu.br \\ Natália Regina Salomão de Freitas ${ }^{3}$ - nataliarfreitas@gmail.com \\ Danielle Manso Muniz Goaçalves ${ }^{4}$ - \\ danny_mmg@yahoo.com.br
}

\section{RESUMO}

Para atender à demanda da atividade turística e propiciar qualidade no atendimento nos serviços, o projeto Caminhando pelas Ruas de Desterro - SC teve como objetivo oferecer a atividade de educação patrimonial junto a trabalhadores do setor terciário da cidade através de caminhadas culturais gratuitas no Centro Histórico de Florianópolis, com a intenção de comparar e promover uma interação dialógica dos participantes com a cidade. Por ser um projeto de extensão vinculado ao ensino, propiciou o aprimoramento da prática profissional das discentes do Curso Técnico em Guia de Turismo, ofertado pelo Instituto Federal de Santa Catarina (IFSC), Câmpus Florianópolis Continente. Dentre os resultados, foi constatada a falta de tempo e disponibilidade do públicoalvo em participar da caminhada.

\section{PALAVRAS-CHAVE}

Educação Patrimonial. Guia de Turismo. Prática \& Técnica Profissional.

\footnotetext{
1 Projeto contemplado e executado com recursos do Edital APROEX Nº 03/2014-2015- da Pró-Reitoria de Extensão e Relações Externas do IFSC.

2 Docente e pesquisadora do IFSC. Coordenadora do projeto "Caminhando pelas ruas de Desterro-SC" - Graduação.

3 Bolsista do projeto - Graduação em Engenharia Civil. Guia de Turismo Regional SC/Nacional/América do Sul.

4 Bolsista do projeto - Graduação em Turismo. Guia de Turismo Regional SC/Nacional/América do Sul.
} 


\section{ABSTRACT}

In order to meet the demand of the tourist activity and to provide quality service in the services, the aim of the project "Walking through the Streets of Desterro - SC" was to offer a patrimonial education activity to city workers through free cultural walks in the Historical Center of Florianópolis, with the intention of comparing and promoting a dialogical interaction of the participants with the city. As an extension project linked to teaching, it provided the improvement of professional practice of students of the technical course in tourism guide, offered by Câmpus Florianópolis Continente of the Federal Institute of Santa Catarina (IFSC), Câmpus Florianópolis Continente. Among the results, it was verified the lack of time and availability of the target public to participate in the walk.

\section{KEYWORDS}

Heritage Education. Tourist Guides. Practice \& Professional Technique.

\section{Introdução}

0 turismo vem crescendo de maneira acelerada e complexa e já se constitui em um dos mais importantes fatores de desenvolvimento social e econômico dos países com vocação turística. As cidades para atender as demandas desse crescimento deparam-se com a necessidade de realizar parcerias entre as administrações públicas, setores privados, organizações sociais, instituições políticas e sociedade civil, pois:

as cidades adquirem, cada dia mais, um forte protagonismo tanto na vida política como na vida econômica, social, cultural e nos meios de comunicação). Pode-se falar das cidades como atores sociais complexos e de múltiplas dimensões. As cidades como atores sociais não se confundem com o governo local, porém, obviamente, incluem-no. (CASTELLS; BORJA, 1996, p. 152)

Dentro dessa complexidade, a promoção turística é realizada através da ação conjunta destes atores sociais, definindo quais os produtos que a cidade irá eleger para representá-la. (CASTELLS; BORJA, 1996). Milton Santos (1996), ao discutir a dimensão material e simbólica do espaço geográfico, define-o como um sistema indissociável de objetos e ações. Neste contexto, dentre os diversos produtos turísticos, encontra-se a oferta cultural que, de acordo com o Relatório BRASIL, afirma que:

a busca pelo produto cultural encontra explicação na necessidade de os indivíduos confrontarem suas origens com a realidade socioeconômica da atualidade. Isso faz com que o turismo cultural represente muito mais do que ver e conhecer estilos de vida, folclore ou arte de outras culturas, mas propicie experimentar uma realidade diferente, encontrando a interação entre o passado e o presente e sinalizando, para alguns, parâmetros do futuro. (2014, p.77)

Em decorrência dessa expansão, mudanças tornam-se significativas e o mercado passa a exigir que a mão de obra seja cada vez mais qualificada. Este é um requisito básico e essencial para qualquer empreendimento, principalmente, para aqueles cujas atividades são exclusivamente de prestação de serviços, como é o caso do turismo (VALLE, 2004).

A qualificação vem no intuito de atender ao que sugere Krippendorf (2003, p.154) que, para um desenvolvimento harmonioso no turismo "é preciso revalorizar as profissões de vocação turística e reforçar a participação da população local em todos os setores". Ainda segundo Petrocchi (1998, p.182), "uma localidade que pretende desenvolver o turismo necessita se preparar para lidar com o público: os visitantes". Para Castells:

a identidade é um processo social, sendo definida como: "fontes de significados e experiências construídas [...] a partir da matéria-prima fornecida pela história, geografia, biologia, instituições de poder e revelações de cunho religioso" (1999, p.23).

Lynch cita que, pelo fato do patrimônio significar a rememoração ou a lembrança da própria ação humana em diferentes tempos e lugares, "todo cidadão possui numerosas relações com 
algumas partes de sua cidade, e a sua imagem está impregnada de memórias e significações" (apud CARVALHO, 2011, p.4). Esclarece 0 autor que aos grupos sociais torna-se necessária a eleição de determinados marcos simbólicos que garantam 0 sentido de permanência e de pertencimento a uma sociedade, uma vez que a aceleração dos contatos e a maior interdependência entre as regiões resultantes das transformações científicas e tecnológicas e da globalização, produzem modificações nas identidades culturais.

De acordo com dados de um levantamento realizado pelo Ministério do Turismo (MTUR) em parceria com o Serviço Brasileiro de Apoio às Micro e Pequenas Empresas (Sebrae), em 2014, Florianópolis (Figura 1) encontrava-se como o décimo destino mais competitivo do país, atraindo turistas e visitantes de várias localidades do Brasil e do mundo. De acordo com Bueno, o território do município de Florianópolis, que abrange uma pequena porção continental e a llha de Santa Catarina, "é constituído por diversos ecossistemas naturais representativos do litoral brasileiro, conformando uma paisagem rica e agradável à vista de quem dela se aproxime" (2006, p.26).

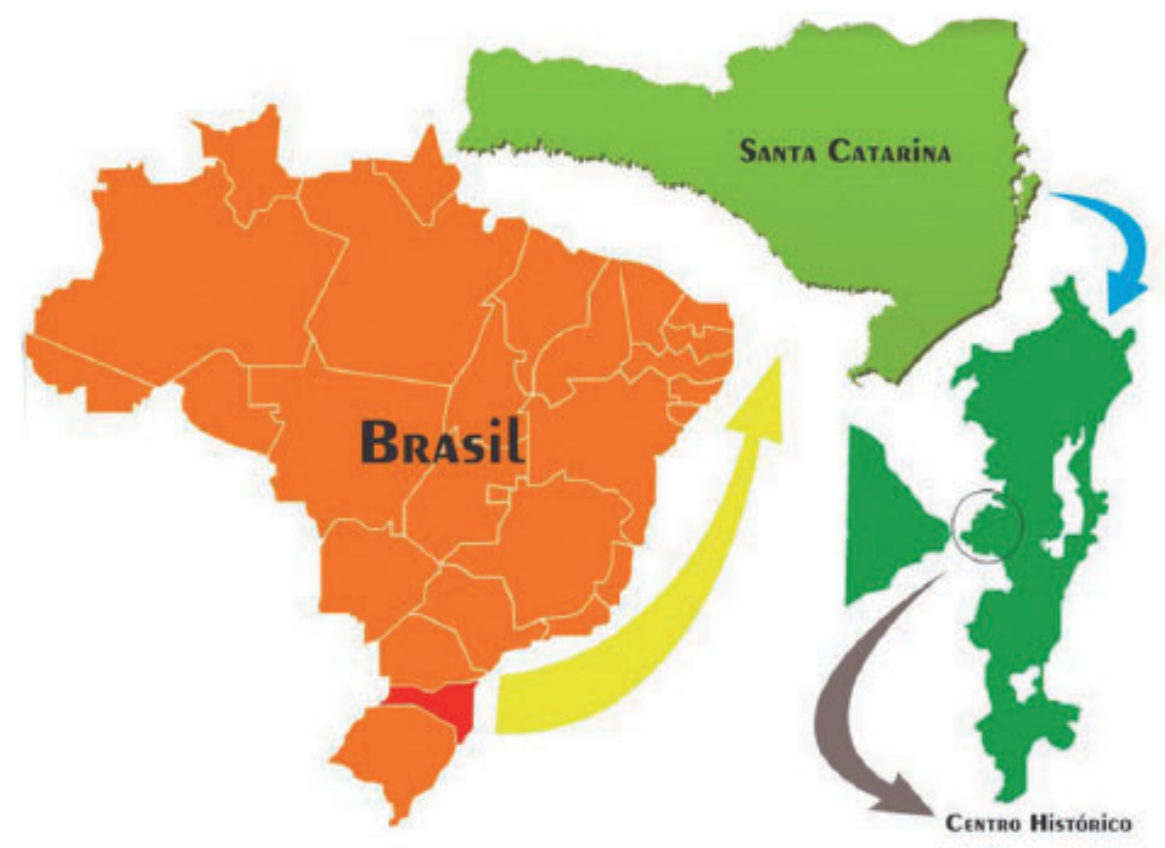

Figura 1: Localização do Centro Histórico em Florianópolis

Fonte: Elaborado pelas autoras.

A antiga póvoa de Nossa Senhora do Desterro, hoje Florianópolis, possui um centro histórico muito rico; um organismo vivo no que diz respeito ao patrimônio histórico e cultural. Caminhando pelas ruas, o morador, turista e/ou visitante tem a oportunidade de circular por lugares de memória.

Segundo Carvalho (2011), o reconhecimento do patrimônio como lugar de memória está ancorado, por exemplo, nas ações públicas de preservação que determinam os sentidos e significados que irão circular nos espaços urbanos. Ainda de acordo com o mesmo autor:

é através das feições urbanísticas, dos monumentos, casarões e prédios históricos, compreendem-se as relações sociais que se encerram nos espaços urbanos, ou seja, as experiências coletivas e pessoais que definem o envolvimento subjetivo entre homem e meio ambiente físico, por um lado, e do outro, entre 0 homem e a identidade. (2011, p.5)

Magalhães (2009), menciona que a educação patrimonial feita transformadora possui caráter político, visando a formação de pessoas capazes de (re)conhecer sua própria história cultural, deixando de ser espectador como na proposta tradicional para tornar-se sujeito, valorizando a busca de novos saberes e conhecimentos, provocando conflitos de versões.

A concepção de educação patrimonial adotada por Magalhães (2009) entende o patrimônio e a memória como elementos fundamentais para a identificação do indivíduo com seu meio, 
o que motiva a ação cidadã, entendendo-a como possibilidade e condição de intervir em sua realidade, pois só haverá envolvimento e comprometimento com o patrimônio, quando houver identificação com ele. Corrobora a citação de Veiga,

estudos desenvolvidos pela UNESCO alertam para a importância das cidades preservarem seus referenciais históricos sob pena de graves efeitos psicológicos em seus habitantes. E, comumente, tem-se dito em adágios preservacionistas que: Só se protege o que se ama; só se ama o que se conhece. (1993, p.18)

No momento em que o trade turístico busca definir um planejamento adequado para a cidade, a ação do Câmpus Florianópolis-Continente (IFSC) busca atender a lacuna da promoção turística junto às questões histórico culturais através da oferta de um produto cultural.

Neste contexto, o objetivo geral do projeto foi promover aos trabalhadores profissionais municipais da limpeza das ruas, vendedores e expositores de feiras de artesanato e feira de produtos alimentícios, funcionários dos comércios, agentes de informação e ambulantes do Centro Histórico de Florianópolis, a oportunidade de participar de maneira dialógica, interativa e lúdica de uma caminhada cultural pelas "Ruas de Desterro" - antigo nome da capital do Estado de Santa Catarina.

Este trabalho foi realizado dentro de um projeto de extensão, denominado "Caminhando pelas Ruas de Desterro - SC", contemplado no edital APROEX 03- 2014/2015 do Instituto Federal de Santa Catarina, apresentando uma proposta de prática profissional, com o intuito de aproximar a tríade do ensino, pesquisa e extensão através da ExperiênciAção profissional que contou com a participação de duas bolsistas - discentes do Curso Técnico em Guia de Turismo, categoria Regional Santa Catarina e Nacional/ América do Sul.

\section{Metodologia}

Com um olhar voltado por um prisma mais filosófico, Minayo considera a pesquisa como "atividade básica das ciências na sua indagação e descoberta da realidade. É uma atitude e uma prática teórica de constante busca de aproximação sucessiva da realidade que nunca se esgota, fazendo uma combinação particular entre teoria e empiria" (1993, p. 23).

Desse modo, no que se refere à natureza do presente projeto ela é aplicada, já que, de acordo com Cooper e Schindler, "[...] tem ênfase na prática e busca revelar respostas para questões específicas relacionadas à ação, desempenho ou necessidades políticas, fornecendo resultados para a prática profissional" (2001, p.15).

Além disso, conforme Kauark "a natureza da pesquisa aplicada, uma vez que objetiva gerar conhecimentos além dos teóricos, volta-se para a aplicação prática dirigida à solução de problemas específicos" (2010, p. 26), o que vem ao encontro da proposta deste projeto.

Quanto ao objetivo, este estudo é caracterizado como descritivo. Segundo Gil, "as pesquisas descritivas procuram descrever as características de uma população ou fenômeno, ou estabelecer relações entre variáveis" (2002, p. 42). Para realizar este tipo de pesquisa, utiliza-se técnicas de coleta de dados, como o questionário e a observação sistêmica. Como apresentado, seu principal propósito é descrever alguma coisa, normalmente, características de um grupo de interesse.

Considerando uma perspectiva de gestão, Malhotra relata que a pesquisa descritiva é realizada para: "descrever as características de grupos relevantes, como consumidores, vendedores, organizações ou áreas de mercado" (2002, p. 2).

Visando o fortalecimento do sentimento de identidade e memória dos valores culturais da comunidade em que vivem, foi elaborado um roteiro cultural com base em um levantamento exploratório dos atrativos históricos culturais e locais de memória do centro de Florianópolis para a estruturação e definição dos locais de percepção e apreciação dos futuros participantes. 
"A valorização do bem patrimonial não é apenas pela sua história ou antiguidade, mas também, e principalmente, apoiando-se em valores e sentimentos de pertença da população em relação ao bem" (GOMES, 2008, p.170). "A riqueza turística de um território é dada pelo seu patrimônio cultural e natural, o qual é estratégico integrar a sua proteção e valorização dentro da perspectiva de desenvolvimento". (GONZÁLEZ; MARTINEZ, 2010, p.5). Assim, o roteiro definido envolveu 6 locais de memória: Catedral, Praça 15, Mercado Público, Miramar, Largo da Alfandega e Casario da Conselheiro Mafra, conforme Figura 2:

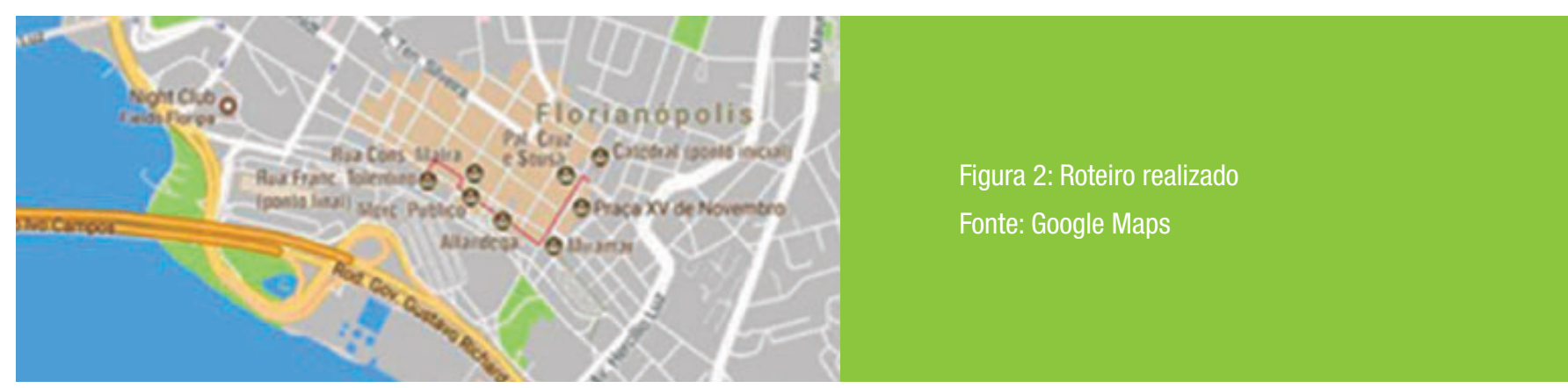

A duração do roteiro foi estimada em aproximadamente 1 hora, realizados sete vezes, no período de março a julho de 2015. Foram convidados para participar do projeto profissionais do setor terciário.

Este público foi definido com a proposta de inserir especificamente as classes de profissionais que atuam diariamente neste espaço urbano. Para atrair este público, foram realizadas entrevistas com questões abertas e a entrega de material de divulgação do projeto em diversas empresas privadas e públicas.

Para a divulgação da oferta da caminhada turística gratuita, utilizaram-se os seguintes meios de comunicação: flyers, contatos telefônicos, fanpage no Facebook, criação de um e-mail específico do projeto (ruasdedesterro.sc@gmail.com) e visitas "in loco", realizando o convite aos participantes para 0 agendamento do roteiro. A Figura 3 apresenta o flyer utilizado para divulgação do projeto.

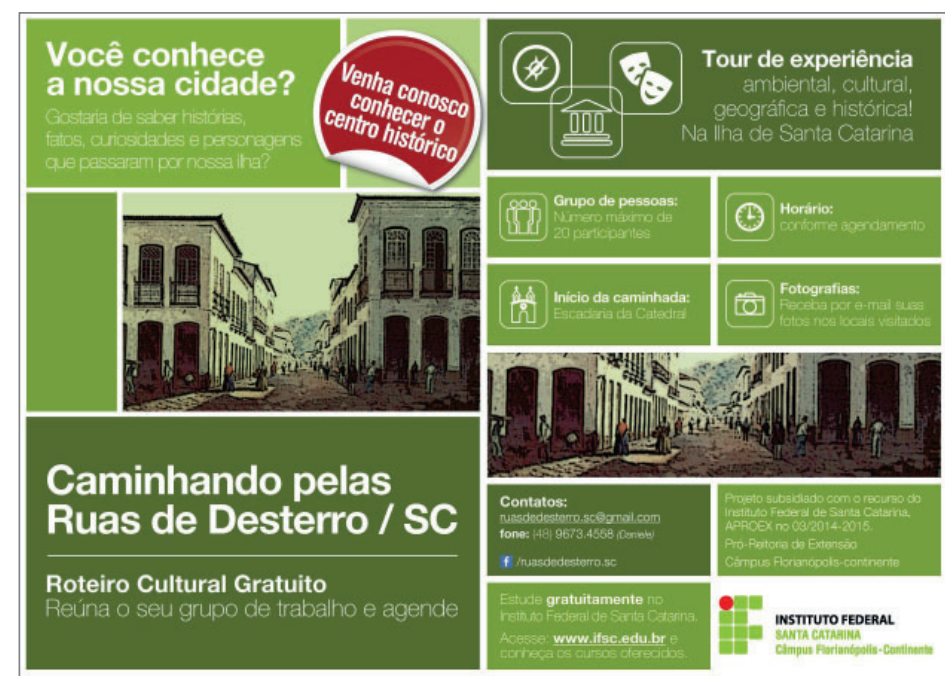

Figura 3: Flyer de divulgação.

Fonte: Elaboração bolsistas e Diretoria de Comunicação - IFSC.

Através da participação em reuniões, que ocorreram junto ao trade turístico para viabilizar parcerias que dariam apoio à divulgação e maior visibilidade ao projeto, foram realizadas visitas ao Instituto de Geração de Emprego e Oportunidade de Florianópolis (Igeof), Câmara dos Dirigentes e Lojistas de Florianópolis (CDL), Camelódromo, Comércios do Centro, Associação do Mercado Público, Associação dos Ambulantes, Correios, Autarquia de Melhoramentos da Capital (Comcap), Feira do Largo da Alfândega, peixarias no Mercado Público, Secretaria do Transporte Urbano de Florianópolis (Setuf) e Secretaria Municipal de Transporte e Mobilidade (SMTM), o qual envolveu mais de 1.500 pessoas.

As fotos tiradas durante o percurso foram encaminhadas para os mesmos (online/impressa) como registro de sua participação, pois segundo Sipp et al. in Ruschmann: 
quando algo é capturado por um aparelho fotográfico, seja uma paisagem, um produto, pessoas ou lugares, as imagens representam mais que uma definição comum; elas denotam fragmentos e continuidade de uma história contada por aqueles que presenciaram dado momento. Por tais razões, as fotografias [...], tornam-se documentos que preservam as cenas, as pessoas, os sonhos, as experiências. (2013, p. 399)

0 material elaborado com o mapa da cidade e fotos antigas foi utilizado como referência no roteiro e na narrativa histórica. A utilização desse recurso encontra referência em citação sugerida por Horta (1996, p.2), o qual afirma que: "0 uso e a compreensão de mapas, plantas, fotografias aéreas, fotos antigas e recentes, documentos originais, arquivos, bibliografia são outras habilidades envolvidas na exploração orientada de um sítio ou monumento histórico".

As Figuras 4, 5 e 6, a seguir, apresentam algumas fotos inseridas no álbum disponibilizado durante a caminhada cultural.

Figura 4: Alfândega e foto aérea.

Fonte: PMF/FCFFC/Centro de Documentação - Casa da Memória.

Figura 5: Foto aérea do Centro Histórico Florianópolis.

Fonte: Centro de Documentação Casa da Memória PMF-FCFFC.

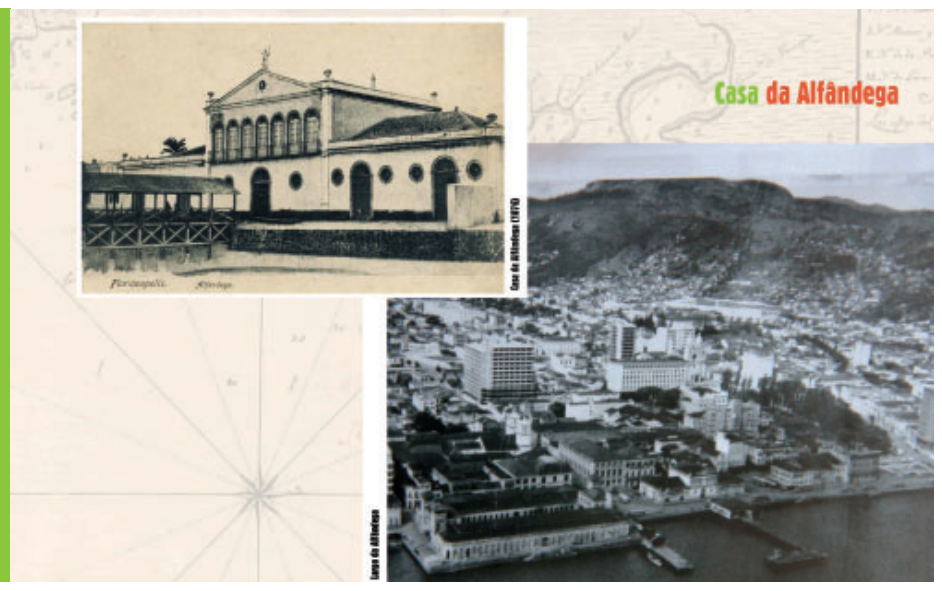

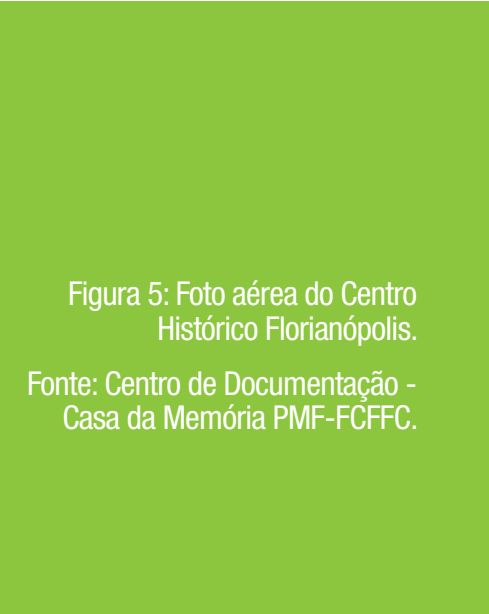

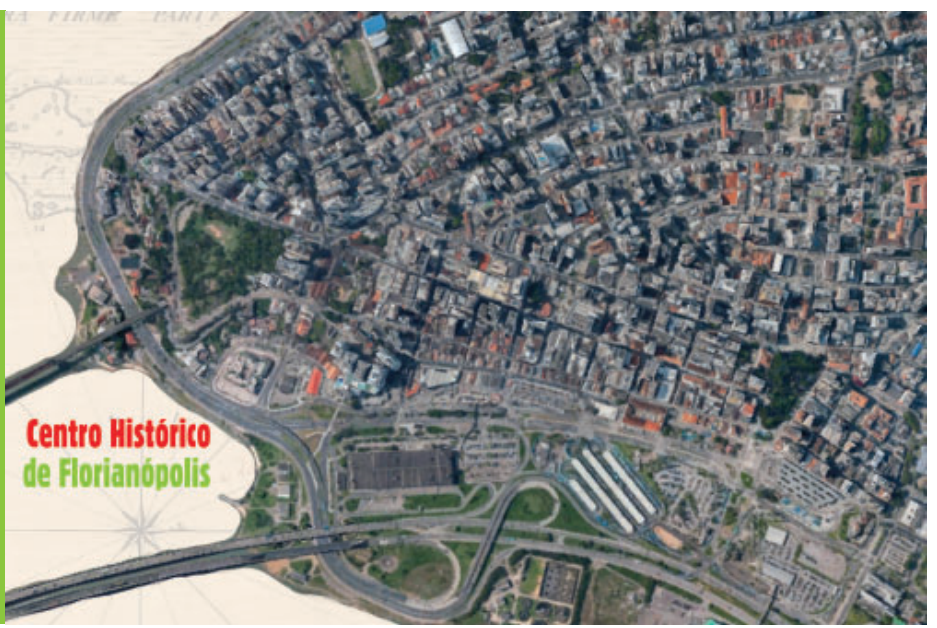

Figura 6: Trapiche do Miramar.

Fonte: Centro de Documentacão Casa da Memória PMF-FCFFC.

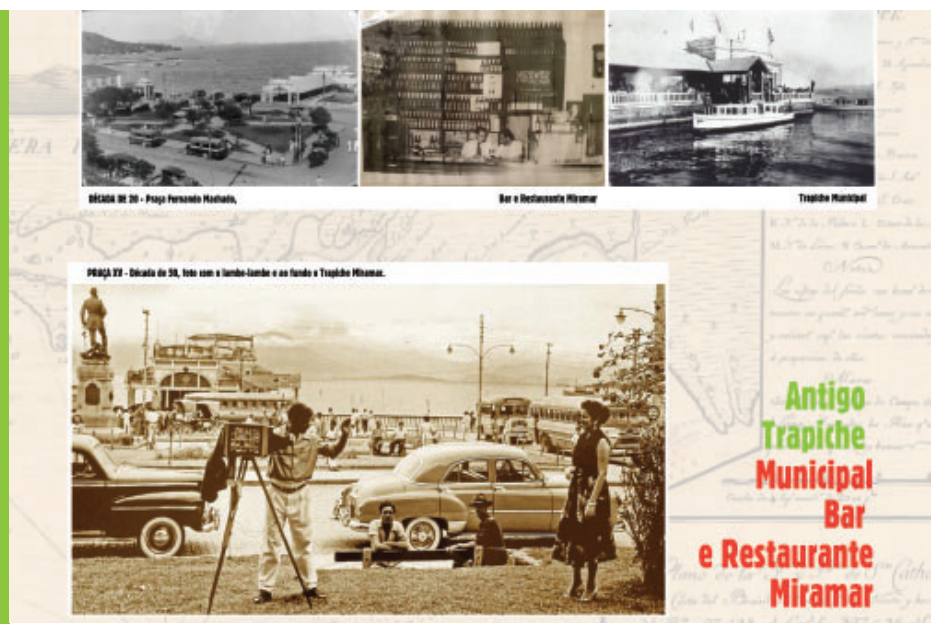


Várias adequações estratégicas e metodológicas foram necessárias diante de dificuldades que foram se apresentando durante a vigência do projeto, dentre elas a adoção da formação de grupos fechados com pré-agendamento de maneira a efetivar a realização dos roteiros e alcançar o número de participantes previstos inicialmente. Para a obtenção da avaliação dos participantes, opinários foram entregues ao final da caminhada, conforme Quadro 1:

\section{OPINÁRIO}

"Caminhando pelas Ruas de Desterro - SC"

Prezados Participantes, a fim de aprimorarmos nossos serviços, gostaríamos que, ao término de seu passeio, você preencha nosso questionário para que possamos continuar mantendo a qualidade esperada por todos aqueles que utilizam nossos serviços. Obrigada.

Serviço: Ótimo Bom Regular Ruim

$\begin{array}{lllll}\text { Apresentação dos Guias ( ) } & \text { ( ) } & \text { ( ) } & \text { ( ) } \\ \text { Conteúdo apresentado } & \text { ( ) } & \text { ( ) } & \text { ( ) } & \text { ( ) } \\ \text { Atrativos visitados } & \text { ( ) } & \text { ( ) } & \text { ( ) } & \text { ( ) }\end{array}$

Qual (is) atrativo (s) Ihe chamou mais a atenção?

Você recomendaria a caminhada para outras pessoas?

( ) $\operatorname{Sim}$ ( ) Não Quem?

Comentários, sugestões. (opcional)

Nome do participante (opcional)

Email;

Data:

Projeto apoiado com recurso do IFSC. Aproex no 03/2014/2015. Realização Câmpus Florianópolis Continente

\section{Resultados e discussão}

0 projeto ofereceu gratuitamente 0 serviço de uma caminhada cultural semanal com a intenção de propiciar à comunidade trabalhadora, que passa a maior parte do seu dia no Centro Histórico de Florianópolis, ciência de que fazem parte da construção da identidade cultural local. Através do seu trabalho seja em órgãos públicos, lojas ou em feiras de artesanato, alimentos ou como moradores locais, o prazer de participar e vivenciar a preservação e 0 desenvolvimento do turismo cultural.

Considera-se de grande importância 0 envolvimento dos órgãos públicos e a participação da população local para o fortalecimento de uma prática social preservacionista, quanto às suas próprias manifestações culturais, locais de memória e paisagens naturais. Para que os trabalhadores pudessem se programar, a divulgação da oferta da caminhada foi realizada com uma semana de antecedência. As ações de articulação foram intensas, embora não tenha tido a aceitação da forma como se esperava, devido à falta de tempo do trabalhador e pelo fato dele associar o centro da cidade como um espaço de deslocamento diário.

Vários horários foram ofertados pelos idealizadores do projeto, ao buscar parcerias junto aos gerentes das lojas, órgãos públicos, responsáveis pelas associações e professores de escolas, no intuito de garantir a participação destes, que prometiam reunir um grupo e confirmar a data e horário de saída, mas depois, cancelavam. 
Verificou-se que o tempo de lazer no próprio espaço de trabalho (Centro) nos finais de semana fica como segunda opção. Estar junto à família e amigos, descansar e realizar outras atividades como: lavar o carro, cuidar do jardim, visitar parentes, foram mencionados em momentos da apresentação da proposta e convite.

Paralelamente, a divulgação foi reforçada através da rede social Facebook, onde se obteve próximo a 300 curtidas, mas nenhum comparecimento no horário, data e local marcado. Diante dos resultados, denota-se que houve uma grande apreciação do projeto através dos números de curtidas e de compartilhamentos, mas somente nessa esfera, suscitando a ideia da falta de uma efetiva atitude de compromisso. No entanto, as sete conduções realizadas atingiram um público de 52 pessoas e o número de participantes foi abaixo do estimado inicialmente no projeto.

A oferta da caminhada cultural gratuita como um estudo exploratório apresentou dificuldades para atrair e motivar os trabalhadores a participarem mais ativamente do roteiro cultural. Outro motivo encontrado para a baixa adesão, foi devido à alta temporada, à grande demanda de trabalho e, consequentemente, a falta de tempo para a participação. 0 volume de material distribuído (5.000 panfletos) despertou o interesse de muitas pessoas em realizarem a caminhada, mas infelizmente, 0 interesse não foi demonstrado efetivamente no comparecimento.

As pessoas que participaram da caminhada manifestaram comentários de que a atividade foi muito boa, interessante, maravilhosa, ótima, e que aprenderam muito. Fizeram sugestões para que o projeto tivesse uma continuidade, ou que se estendesse até freguesias do Ribeirão da llha e de Santo Antônio de Lisboa. Outros sugeriram que o percurso fosse mais longo e tivesse mais tempo de passeio; mesmo as bolsistas, aumentando em algumas vezes o tempo da atividade. Vários participantes afirmaram que fariam o roteiro novamente e que convidariam novos participantes, pois viram a oportunidade do enriquecimento de seus conhecimentos pessoais. 0 retorno por parte daqueles que participaram do roteiro foi satisfatório.

Os resultados obtidos através do opinário, entregues ao final da caminhada, encontram-se na Tabela 2.

\begin{tabular}{cccc}
\hline $\begin{array}{c}\text { Apresentação das } \\
\text { Guias de Turismo }\end{array}$ & Conteúdo Apresentado & Atrativos Visitados & Outros 18,86\% \\
\hline Ótimo - 96,22\% & Ótimo - 53,01\% & Ótimo - 77,35\% & Ótimo - 70,00\% \\
\hline Bom - 03,78\% & Bom - 46,99\% & Bom - 22,65\% & Bom - 30,00\% \\
\hline
\end{tabular}

Um dos participantes citou a importância do profissional Guia de Turismo na atuação do turismo da cidade, assim como a necessidade de maiores investimentos e melhorias na infraestrutura, tanto para moradores como turistas. No entanto:

\footnotetext{
"é preciso refletir sobre diferentes conceitos que, em nossa opinião, são necessários para internalizar o papel importante do guia de turismo na conservação do Patrimônio Cultural e o desenvolvimento sustentável do Turismo, com base em uma interpretação eficiente e efetiva desse patrimônio (GONZÁLEZ; MARTíNEZ, 2010, p.3).
}

Neste contexto, a existência de profissionais capacitados para conduzir e aproximar a história local da sociedade já é uma realidade no município de Florianópolis, devido à oferta do curso de Guia de Turismo pelo Câmpus Florianópolis-Continente (IFSC), desde 2011.

Embora existam diversas formas da comunicação humana com base nas artes, ou através de impressos ou mídia, nada substitui a interpretação ao vivo quando realizada por guias e condutores sensíveis ao ambiente e às necessidades dos visitantes/turistas (MURTA, 2005, p.14). No entanto, poucos participantes tinham uma ideia prévia da história real da colonização açoriana. Encantaram-se com os mitos, lendas, arquitetura, cultura, tradições e os demais significados do contexto histórico do centro, ressaltando dentre os vários pontos os nomes dados à llha de Santa Catarina: Vila de Nossa Senhora do Desterro, Cidade de Desterro e, por fim, Florianópolis. 
A interferência de um grande contingente de pessoas de outras origens e a existência de uma população minoritariamente nascida no local propicia a multiculturalidade. No entanto, atitudes de respeito e proteção à identidade sócio-ambiental/cultura requerem ações conscientizadoras em cada localidade, junto às comunidades e aos visitantes.

0 fato dos passeios serem oferecidos gratuitamente causou certa desconfiança nos participantes. Embora apresentassem bastante interesse quanto à proposta, alguns queixavam-se da sua atual situação de trabalho (questões financeiras, falta de valorização) e não vislumbravam a possibilidade de participar do roteiro cultural por falta de tempo ou com a preocupação de perder uma venda.

Para atrair a participação do público-alvo, foi proposta a liberação dos funcionários um pouco mais cedo do seu horário de trabalho junto aos responsáveis e empregadores, mas os mesmos, por razões financeiras, não viam a possiblidade dessa participação. Mesmo com a proposta de realizar a caminhada após a saída do trabalho, não houve adesão.

Com essas barreiras encontradas, novas táticas foram adotadas para atrair não somente os trabalhadores, mas também moradores da cidade que pudessem se interessar pela questão do patrimônio histórico cultural. Levando-se em conta que desde 1970 há um movimento crescente de pessoas de outros estados e cidades que vêm morar na llha, vislumbrou-se a possibilidade de atraí-las com conteúdo teórico e metodologias aprendidas na unidade curricular de Técnica \& Prática Profissional do Curso Técnico em Guia de Turismo.

Diante disso, no intuito de divulgar e alcançar um número maior de participantes, com base em Pereira (2013, p. 168), que sugere que a instituição pública de ensino IFSC deva "adotar a mídia social para se comunicar com alunos, servidores e comunidade externa, como evidência de que, também na área da educação, as organizações devam adaptar-se às mudanças e tendências de cada época". Com esse embasamento, foi realizado então, um "impulsionamento" na ferramenta de comunicação do Facebook, o que alavancou as curtidas, compartilhamentos e participação dos eventos, agendados para todos os sábados.

Mesmo com algumas confirmações através dos eventos criados no Facebook, muitas das pessoas que sinalizavam que iriam participar da caminhada não compareciam, o que nos obrigou a anunciar, na própria página do Facebook, que só seriam atendidas as pessoas que efetivamente confirmassem via e-mail ou contato telefônico. 0 resultado final de participação nos 7 guiamentos realizados, discriminados pelo tipo de agendamento, estão apresentados a seguir na Tabela 4.

\begin{tabular}{cccccc}
\hline $\begin{array}{c}\text { Número da } \\
\text { Condução }\end{array}$ & $\begin{array}{c}\text { Data do } \\
\text { Passeio }\end{array}$ & $\begin{array}{c}\text { Número de } \\
\text { participantes }\end{array}$ & $\begin{array}{c}\text { Pessoas } \\
\text { confirmadas via } \\
\text { Evento Facebook }\end{array}$ & $\begin{array}{c}\text { Comparecimento } \\
\text { através } \\
\text { do Facebook }\end{array}$ & $\begin{array}{c}\text { Tipo de } \\
\text { Agendamento }\end{array}$ \\
\hline 1 & $13 / 12 / 2014$ & 5 & 0 & 0 & Pessoalmente \\
\hline 2 & $01 / 04 / 2015$ & 7 & 0 & 0 & Email \\
\hline 3 & $10 / 04 / 2015$ & 7 & 0 & 0 & Pessoalmente \\
\hline 4 & $18 / 04 / 2015$ & 6 & 0 & 0 & Email \\
\hline 5 & $27 / 04 / 2015$ & 13 & 0 & 0 & Pessoalmente \\
\hline 6 & $02 / 05 / 2015$ & 8 & 13 & 3 & Email \\
\hline 7 & $09 / 05 / 2015$ & 6 & 10 & 2 & Pessoalmente \\
\hline
\end{tabular}

Tabela 4: Data dos guiamentos, números de participantes e tipo de agendamento

Fonte: Resultados do projeto (2015).

Nesta oportunidade, foi feita a divulgação via folders dos cursos ofertados pelo Instituto Federal de Santa Catarina - IFSC junto aos participantes; os quais se surpreenderam com a informação da gratuidade e a oportunidade de frequentar um curso com elevado nível de ensino. 


\section{Conclusões}

É de grande importância 0 envolvimento dos órgãos públicos e instituições privadas quanto à participação da população local para o fortalecimento de uma prática social preservacionista, quanto às suas próprias manifestações culturais, locais de memória e paisagens naturais.

0 papel do guia de turismo acaba sendo decisivo e valioso ao planejar a sua gestão, quanto à interpretação nesse processo, para propiciarem uma experiência autêntica aos visitantes, junto aos diferentes locais da cidade, em virtude de seus recursos históricos culturais, no intuito de desenvolver no visitante atitude de respeito e valorização.

Os participantes foram quantitativamente poucos, mas qualitativamente pode-se considerar que foram sensibilizados e se transformaram em apreciadores dos atrativos histórico-culturais da cidade em que vivem. A coleta dos resultados finais foi significativa e demonstrou que, para a implementação de uma práxis cultural, exige-se uma articulação de médio, longo prazo.

Paralelamente considera-se que a implementação gratuita de um projeto cultural promovido pela instituição é de grande importância, assim como a manutenção contínua dos recursos para a educação, no intuito de garantir a formação e a inserção profissional no âmbito do Turismo e contribuir para o fomento do turismo cultural na llha de Santa Catarina, sob uma perspectiva transdisciplinar, exploratória e articuladora entre o público e o setor privado.

Denota-se que o projeto apresenta a oportunidade de se tornar uma atividade de extensão permanente; da qual uma opção a ser considerada seria a inserção da proposta dentro da ementa do curso.

Diante do exposto, pode-se concluir que a articulação do ensino aliada à extensão vai ao encontro dos objetivos institucionais do Instituto Federal de Santa Catarina - IFSC, pois permite ao estudante vivenciar a prática durante a formação, ao mesmo tempo em que promove um diálogo estreito da instituição com a comunidade externa.

\section{Referências}

ALBUQUERQUE, Umbelino Peregrino de. Patrimônio Cultural: uma construção da cidadania in: Educação patrimonial: reflexões e práticas. / Átila Bezerra Tolentino (Org.) - João Pessoa: Superintendência do Iphan na Paraíba, 2012.

BRASIL. IBGE. Instituto Brasileiro de Geografia e Estatística. Disponível em: <http:// www.cens02010.ibge.gov.br/sinopse/index.php?dados $=6 \& u f=00>$. Acesso em: 30 mai. 2015.

BRASIL. IBGE. Instituto Brasileiro de Geografia e Estatística. Disponível em: <http:// cidades. .bge. gov.. r $/$ xtras/temas. php?lang $=\&$ codmun $=420540 \& i d t e m a=130 \&$ search $=$ san ta-catarinalflorianopolislestimativa-da-populacao-2016->. Acesso em: 27 fev. 2016.

BRASIL MTUR. MINISTÉRIO DO TURISMO. Disponível em: <http://g1.globo.com/sc/ santa-catarina/verao/2015/noticia/2014/12/florianopolis-e-0-10-destino-turistico-maiscompetitivo-do-pais-aponta-mtur.html>. Acesso em: 13 jul. 2015.

BRASIL. MTUR. MINISTÉRIO DO TURISMO. Índice de Competitividade do Turismo Nacional RELATÓRIO BRASIL 2014. Disponível em: <http://www.dadosefatos.turismo.gov. br/export/sites/default/dadosefatos/outros_estudos/downloads_outrosestudos/Relatorio_ Brasil_2014_web.pdf>. Acesso em: 13 jul. 2015.

BUENO, Ayrton Portilho. Patrimônio paisagístico e turismo na llha de Santa Catarina: a premência da paisagem no desenvolvimento sustentável da atividade turística. São Paulo, 2006. Tese (Doutorado - Área de Concentração: Projeto de Arquitetura) - Faculdade de Arquitetura e Urbanismo da Universidade de São Paulo. Disponível em: <http://www.teses.usp.br/teses/ disponiveis/16/16138/tde-28022007-124752/pt-br.php>. Acesso em 30 jan. 2015. 
CARVALHO, Karoliny Diniz. Memória Turismo e Política Patrimonial: Análise da revitalização do centro histórico de São Luís, Maranhão (Brasil) in: TURYDES Revista de investigación em turismo y desarrollo local. Vol 4, № 10 (julio/julho 2011). Disponível em: <http://www. periodicos.ufpel.edu.br/ojs2/index.php/lepaarq/article/view/1322>. Acesso em 30 jan. 2015.

CASTELLS, Manuel. 0 Poder da identidade. São Paulo: Paz e Terra, 1999.

CASTELLS, Manuel; BORJA, Jordi. (Trad.: Omar Ribeiro Thomaz). As Cidades como Atores Políticos in: Novos Estudos. CEBRAP no 45, julho 1996. pp. 152-166. Disponível em: $<$ http://www.acsmce.com.br/wp-content/uploads/2012/10/AS-CIDADES-COMO-ATORESPOL\%C3\%8DTICOS.pdf>. Acesso em 30 jul 2015.

COOPER, Donald R.; SCHINDLER, Pamela S. Métodos de pesquisa em administração. 7.ed. Porto Alegre: Artmed, 2001.

GIL, Antônio Carlos. Como elaborar projetos de pesquisa. 4. ed. - São Paulo: Atlas, 2002.

GOMES, Mariana Elias. A Semana Santa em Mariana, MG: estudo da relação entre patrimônio imaterial e turismo. In: Revista Urutágua - revista acadêmica multidisciplinar $-\mathrm{N}^{0} 15-$ abr./mai./jun./jul. 2008 - Quadrimestral - Maringá - Paraná - Brasil - ISSN 1519-6178 Disponível em: <http://www.urutagua.uem.br/015/15gomes.pdf>. Acesso em: 20 jan. 2016.

GONZÁLEZ, N. F.; MARTíNEZ, J. L. B. El guía de turismo y la conservación del patrimonio cultural. In: TURyDES Revista de Investigación en turismo y desarrollo local. vol. 3, no 8 (septiembre/ 2010).

HORTA, Maria de Lourdes Parreira. Educação Patrimonial. Disponível em: <https:www. google.com.br/webhp?sourceid-chromeinstant\&ion=1\&espv=2\&ie=UTF8\#q=Educa\%C3\%A $7 \%$ C3\% 4 A30+Patrimonial+PGM+3+\%E2\%80\%93+OS+MONUMENTOS+E+CENTROS+H IST\%C3\%93RICOS> Acesso em: 30 mai. 2015.

KAUARK, Fabiana; MANHÃES Fernanda Castro; MEDEIROS, Carlos Henrique. Metodologia da pesquisa: guia prático. Itabuna: Via Litterarum, 2010.

KRIPPENDORF, J. Sociologia do turismo: para uma nova compreensão do lazer e das viagens. São Paulo: Aleph, 2003.

MAGALHÃES, Leandro Henrique. "Educação Patrimonial: uma análise conceitual." A construção de políticas patrimoniais: ações preservacionistas de Londrina, Região Norte do Paraná e Sul do país. Londrina: UniFil (2009): 65-77.

MAGALHÃES, Leandro Henrique; Branco, Patricia Martins Castelo. Patrimônio, Memória e Turismo: Um Exercício do Olhar: Rev. Perspec. Contemp. Campo Mourão, v.1, n.1, jan./ jul., 2006.

MALHOTRA, N. Pesquisa de marketing: uma orientação aplicada. 6. ed. Porto Alegre: Bookman, 2011. 768p.

MINAYO, Maria Cecília de Souza. 0 desafio do conhecimento. São Paulo: Hucitec,1993.

MORAES, C.C.P. et al. 0 Ensino de História e a Educação Patrimonial: Uma Experiência de Estágio Supervisionado. Revista da UFG. vol. 07, n. 02, dez. 2005. Disponível em: <www. proec.ufg.br>. Acesso em : 29 de jul.2015.

MURTA, Stela Maris; ALBANO, Celia (Org.). Interpretar o Patrimônio: um exercício do olhar. Belo Horizonte: UFMG / Território Brasilis, 2002.

PEREIRA, Daniel Agustin. Mídias sociais como estratégia em instituições de ensino: 0 caso do Instituto Federal de Santa Catarina. Florianópolis: Publicação do IFSC, 2013.

PETROCCHI, Mario. Turismo: planejamento e gestão. São Paulo: Futura, 1998.

SANTOS, Milton. A natureza do espaço: técnica e tempo, razão e emoção. 2. Ed. São Paulo: Hucitec, 1996 
SIPP et al in: RUSCHMANN, Doris Van de Meene. Turismo, ensino e práticas interdisciplinares. Barueri: Manole, 2013.

VALLE, I. A. de. A Profissão de Guia de Turismo: Conhecendo o Passado e o Presente para Projetar o Futuro. 2004. 101p. Dissertação (Mestrado em Cultura e Turismo). UESC, Ilhéus, 2001.

VEIGA, Eliane Veras da. Florianópolis: Memória Urbana. 3. ed., Florianópolis: Fundação Franklin Cascaes, 1993. 